\title{
Hacer Cine en España
}

\section{José Antonio Bello Cuevas}

Recibido: 30.10.2012

Aceptado: 05.11.2012

\section{Resumen}

El presente trabajo es una visión personal de la actividad cinematográfica española del período 2001-2011, en algo más de la primera década del siglo XXI. Refrenda las virtudes y defectos de nuestro cine. Su particularidad le diferencia, de manera notable, del resto de la cinematografía europea, aunque su calidad artística y técnica sigue siendo equiparable, por no decir superior, en algunos casos, a la de los países de nuestro entorno.

El trabajo es la continuación del publicado en Cuadernos de Documentación Multimedia, n" 19 de marzo de 2008, habiendo rectificado y ampliado sus datos.

\section{Palabras clave}

Cine Español. Producción. Distribución. Exhibición.

\section{Summary}

This work is a general and personal vision of Spanish cinematographic activity for the period 2001-2010, in the first decade of the 21st century. It allows seeing that the strengths and weaknesses of our film remains; its idiosyncrasy distinguishes it, most notably, from the rest of the European cinema, Although his artistic and technical quality remains comparable, if not exceeding, in some cases, the countries of our environment.

The work follows on from the one published in Cuadernos de Documentación Multimedia, $\mathrm{n}$ ". 19 of March 2008, having corrected and expanded their data.

\section{Keywords}

Spanish Cinema. Production. Distribution. Exhibition. 


\section{LA PELÍCULA}

La película es un producto sui géneris, un producto destinado a ser consumido en un mercado enormemente competitivo. Para iniciar un proyecto de rodaje de una película hay que partir de una idea o de un guión que suscite el interés de posibles coproductores, tener la posibilidad de acceder a las subvenciones públicas, poder vender los derechos de antena a televisiones públicas y/o privadas y contar con una distribución adecuada de la película. Solucionados estos puntos primordiales, prosiguen distintas fases del proceso de producción:

- La preproducción

- El rodaje

- La postproducción

- La distribución

- La promoción

\section{DE LA IDEA A LA PANTALLA}

Para que una historia escrita sobre el papel se convierta en obra cinematográfica es fundamental su desarrollo en un guión de calidad y su presumible poder de convocatoria entre los eventuales espectadores. Entre los profesionales se suele decir: "Con buen guión se puede hacer una buena película, una película aceptable o una mala película; con un mal guión, sólo se puede hacer una mala película".

\section{EL GUIÓN: ELEMENTO FUNDAMENTAL EN EL PLAN DE PRODUCCIÓN}

Una vez escrito el guión de la película, se puede ir planteando una valoración aproximada del coste de la película, aunque en este momento es imposible asegurar la fiabilidad del producto. El Productor puede tener una participación relativamente activa en la elaboración del guión, un concurso más o menos determinante en el trazo de las líneas maestras de la historia; hay productores que confían en el equipo creativo, el guionista y/o el director, y que no consideran pertinente su intervención que coexisten con los que se involucran directamente en la elaboración del guión. El emplear ciertos criterios economistas es fundamental para elegir el guión:

- Seleccionar cuál es el mercado al que se dirige la historia.

- Percibir las cualidades internas de la historia: tema, conflictos existentes, carga dramática o cómica de los personajes, etc.; es decir, todos aquellos elementos que contribuyan a captar el interés del público.

- Concretar el coste del proyecto: es necesario identificar aquellos importes de producción que repercuten en su magnitud económica.

- Establecer o revisar los valores propios de la producción, o aquellos elementos que enfaticen su interés: reparto técnico y artístico, localizaciones, ambientación, efectos especiales, etc.

- Evaluar la calidad comercial que tiene la película, narrando en ella los valores que repercutirán en el espectador.

El coste medio de un guión en 2011 fue de $593.300 €$, un 2,41\% de presupuesto total de una película. Una vez elegido el guión y decidida la puesta en marcha del rodaje de una película, los primeros pasos son: 
- Elección del director.

- Contratación el equipo técnico.

- Contratación de los actores y actrices protagonistas, principales y secundarios.

- Conseguir una distribución idónea y, si fuera posible, un anticipo de distribución.

- La promoción. Campaña publicitaria, antes, durante y después del rodaje, para suscitar el interés de espectadores, con una presencia frecuente en los medios de comunicación.

El convencimiento y el entusiasmo del productor y del equipo técnico y artístico por la historia son fundamentales para que el rodaje se desarrolle sin inconvenientes y no lo lleve a tomar decisiones de riesgo, e incluso contrarias a la lógica del mercado.

\section{PRODUCCIÓN}

El Productor, como iniciante y patrocinador de una producción cinematográfica, debe lograr apoyos económicos y profesionales para llevar a cabo el proyecto: conseguir acuerdos ventajosos para su distribución y exhibición. Hacer una buena película no es suficiente si no se cuenta con las vías abiertas para que llegue a las pantallas. De alguna manera, el productor tiene que vender la piel del oso antes de matarlo.

En España una productora no suele realizar más de dos películas anuales. Solo 36 con 2 y 7 con 3/4 de las 234 empresas activas en 2009. En nuestra industria algunos productores son, en algunos casos, profesionales de otras ramas u oficios, (directores/actores, técnicos/actores) que se asocian para realizar una película independiente, artesanos de una industria que se caracteriza por su atomización empresarial; las productoras que acometen solo una producción al año no son un modelo a seguir: si la película es rentable, la productora pasará a realizar otra, pero si fracasa el futuro de la empresa queda hipotecado o desaparece, cosa frecuente en nuestra industria cinematográfica. El momento más delicado de una película, visto desde la perspectiva financiera, se da a la hora de amortizar la inversión, cuando la película entra en la fase de distribución y exhibición.

Con el objeto de minimizar el riesgo que supone una producción cinematográfica, el proceso más seguro es establecer acuerdos puntuales con otras productoras, nacionales, europeas o iberoamericanas, con empresas de televisiones u otras empresas de gestión; de este modo se amplían mercados, reducen los riesgos de posibles pérdidas, y se afianzan los posibles beneficios. La cooperación no siempre responde solo a un fin económico, sino que el contar con más presupuesto se puede abordar proyectos de mayor calidad y por ello contar con una mayor promoción en los mercados, nacional y extranjero. El momento más delicado de una película, es la de amortizar la inversión, cuando la película entra en la fase de distribución y exhibición.

El reto del cine español es doble: producir con mayor calidad y llegar a un público acostumbrado al cine americano. 


\section{EL MOMENTO ACTUAL DE LA PRODUCCIÓN ESPAÑOLA}

A la espera de la publicación de los datos definitivos de 2011, durante el año 2010 se continuó dando impulso a la creatividad, con películas de ficción, documentales y de animación. Se mantuvo en el sector de producción la tendencia creciente de los últimos años, realizándose 200 largometrajes, De estos largometrajes, 49 se han realizado en régimen de coproducción con otros países, cifra muy similar a la de 2009 en que se hicieron 51 coproducciones. Este sistema de producción se afianza como medio básico para la salida de nuestro cine al mercado exterior, y para rentabilizar las grandes inversiones iniciales que se necesitan para producir un largometraje.

Argentina, Francia y Portugal, han sido los países con los que más se ha coproducido, habiéndose alcanzado con ello la cifra más elevada de los últimos 25 años.

De los 200 largometrajes producidos en el año 2010, 122 son películas de ficción, 66 son documentales, y 12 de animación; ambos tipos de películas están aumentando considerablemente en los últimos años.

El número de cortometrajes producidos en el año ha sido de 240, prácticamente la misma cifra de 2009, que fueron 241.

El coste medio de una película en 2010 fue de 2,4 millones de euros frente los 3,2 millones en 2009; el coste puede que se considere competitivo, pero esta diferencia, sin duda ha repercutido negativamente en las diversas actividades que integran el proceso de producción, y en la promoción y marketing de la película.

Diversas asociaciones profesionales y entidades de gestión vienen solicitando al Gobierno que promulgue una legislación audiovisual que posibilite la estabilidad y el crecimiento de la industria.

La enorme competitividad del cine norteamericano, que alcanza una cuota cercana al $70 \%$, "obliga» a que exista una legislación de ayudas, subvenciones y fomento del cine, en España y en Unión Europea, para preservar la identidad cultural, hasta que la industria pueda competir en igualdad de condiciones con el gigante estadounidense.

\begin{tabular}{lrrrrrrrrrrr}
\hline \multicolumn{10}{c}{ Producción cinematográfica en España 2001 - 2011* } \\
\hline Largometrajes & 200 & 200 & 200 & 200 & 200 & 200 & 200 & 200 & 200 & 201 & 201 \\
& 1 & 2 & 3 & 4 & 5 & 6 & 7 & 8 & 9 & 0 & 1 \\
$\begin{array}{l}\text { Producción } \\
\text { nacional. }\end{array}$ & 66 & 80 & 68 & 92 & 89 & 109 & 115 & 124 & 136 & 152 & 151 \\
$\begin{array}{l}\text { Coproducciones } \\
\text { Total }\end{array}$ & 40 & 57 & 42 & 41 & 52 & 41 & 57 & 49 & 51 & 49 & 48 \\
\hline
\end{tabular}

\begin{tabular}{rrrrrrrrrrr}
\hline \multicolumn{10}{c}{ Cortometrajes } \\
\hline 2001 & 2002 & 2003 & 2004 & 2005 & 2006 & 2007 & 2008 & 2009 & 2010 & 2011 \\
169 & 171 & 137 & 185 & 161 & 209 & 156 & 210 & 241 & 240 & 249 \\
\hline
\end{tabular}


Datos obtenidos en los boletines del ICAA y en la revista ACADEMIA n" 189, mayo 2012.

España debe defender en el marco de la U.E. que nuestras películas, no deben ser tratadas como meras mercancías y, por tanto, la necesidad de proteger su carácter de creación artística y cultural. La labor de las diversas asociaciones profesionales, culturales y entidades de gestión, han estar orientadas a fortalecer la inversión privada.

La normativa vigente obliga a las diversas cadenas de TV a que inviertan el $5 \%$ de sus beneficios, en proyectos viables, ello ayuda a mantener y mejorar la estructura industrial, con el consiguiente aumento de puestos de trabajo, la renovación tecnológica y mejora de futuro del sector.

Esta norma de obligado cumplimiento, aún vigente, viene siendo rechazada periódicamente por el sector televisivo de carácter privado y, al parecer, va a ser derogada en la próxima ley de lo audiovisual.

\section{LA DISTRIBUCIÓN}

Durante el año 2011 se observa un leve descenso con respecto al año 2010 en cuanto a la distribución de largometrajes españoles y extranjeros. Se mantiene la tendencia de años precedentes en cuanto a efectuarse una distribución intensiva y extensiva a la vez: mayor número de copias en menor tiempo de explotación.

Hubo una mayor importación de cine europeo y menor de Estados Unidos; no obstante sigue dominando la presencia de éste último en el mercado.

Cada vez son más las que se distribuyen en dos versiones, doblada y subtitulada simultáneamente, ya que han sido más de la mitad las películas distribuidas utilizando este sistema, tendencia que se va observando en los últimos años, en 2010, 113 películas extranjeras se han distribuido en versión doblada, 41 en versión subtitulada y 180 en ambas versiones simultáneamente.

El número de copias en el mercado para explotación en salas, en el año 2010, de películas extranjeras fueron 46.406 copias; 60 películas se han comercializaron con más de 300 copias y 18 con más de 500. En 2009 fueron 45.486 las copias en explotación; 56 de ellas se explotaron con más de 300 copias y 12 con más de 500 .

Respecto al cine español se observa, igual que en producción, una tendencia creciente, ya que el número de películas españolas que se han exhibido en el año 2010 es de 367. El elevado número de títulos dificulta la comercialización ya que al producirse una fuerte concurrencia de títulos en el mercado acorta su permanencia; en 2011 el número de películas españolas en cartel fue de 351 .

El sector de distribución, más reducido que el de producción, también presenta diferencias de dimensión empresarial: frente a grandes distribuidoras entre las que se encuentran las filiales de las "majors" americanas, se encuentran pequeñas empresas de ámbito nacional o local. 
Aunque este segundo grupo encuentra dificultades para incorporarse a un mercado competitivo, hay que observar que algunas distribuidoras independientes comercializan productos de calidad y que obtienen un elevado éxito de público. Sin embargo su situación en el mercado sigue siendo frágil y dificultosa, y la dependencia de las televisiones a la hora de vender sus películas, es básica para una subsistencia equilibrada. A veces la fuerza del boca a boca permite la permanencia en cartel de una película española, esto significa que se incrementará el importe de la subvención automática del 15\% que el ICAA otorga por el rendimiento de una película en las salas.

\begin{tabular}{lcccccccccccc}
\hline \multicolumn{10}{c}{ Actividad del sector 2001-2011* } \\
\hline $\begin{array}{l}\text { Distribución } \\
\text { en salas }\end{array}$ & 2001 & 2002 & 2003 & 2004 & 2005 & 2006 & 2007 & 2008 & 2009 & 2010 & 2011 \\
$\begin{array}{l}\text { Películas } \\
\text { españolas. }\end{array}$ & 339 & 350 & 411 & 356 & 352 & 372 & 386 & 394 & 365 & 367 & 346 \\
$\begin{array}{l}\text { Películas } \\
\text { extranjeras. }\end{array}$ & 1.492 & 1.527 & 1.505 & 1.439 & 1.378 & 1.376 & 1.390 & 1.258 & 1.116 & 1.188 & 1.086 \\
\begin{tabular}{l} 
Total \\
\hline
\end{tabular} & 1.831 & 1.877 & 1.916 & 1.795 & 1.730 & 1.748 & 1.776 & 1.652 & 1.481 & 1.555 & 1.432 \\
\hline
\end{tabular}

*Datos obtenidos en los boletines del ICAA y en la revista ACADEMIA n" 174, enero 2011.

Cuadro laborado por el autor.

\begin{tabular}{rrrrrrrrrrr}
\hline \multicolumn{10}{c}{ Distribución en vídeo } \\
\hline $\mathbf{2 0 0 1}$ & 2002 & 2003 & 2004 & 2005 & 2006 & 2007 & 2008 & 2009 & 2010 & 2011 \\
$\mathbf{3 . 2 9 8}$ & 3.708 & 4.185 & 4.240 & 5.291 & 6.468 & 6.765 & 5.381 & 4.316 & 3.643 & 3.327 \\
\hline
\end{tabular}

*Datos obtenidos en los boletines del ICAA.

Es sector se encuentra a las puertas de una necesaria renovación y evolución en su funcionamiento, al incorporarse al mercado audiovisual los nuevos soportes, que sin duda incidirán en los sistemas de distribución de los productos cinematográficos. La posible integración o interrelación de la producción y la distribución podrá favorecer a ambos sectores siempre que los acuerdos entre ambos complementen sus respectivos objetivos

\begin{tabular}{lrrrrrrrrrrr}
\hline \multicolumn{10}{c}{ Espectadores (millones) } \\
\hline & 2001 & 2002 & 2003 & 2004 & 2005 & 2006 & 2007 & 2008 & 2009 & 2010 & 2011 \\
Española & 26,2 & 19,01 & 21,73 & 19,28 & 21,29 & 18,77 & 15,8 & 14,36 & 17,48 & 12,93 & 15,52 \\
Extranjera & 120,6 & 121,7 & 115,74 & 124,64 & 106,36 & 102,88 & 101,14 & 93,45 & 92,51 & 88,67 & 82,82 \\
Total & 146,8 & 140,71 & 137,47 & 143,93 & 127,65 & 121,65 & 116,93 & 107,81 & 109,99 & 101,6 & 98,34 \\
\hline \multicolumn{11}{c}{ *Datos obtenidos en los boletines del ICAA. }
\end{tabular}

El apoyo del ICAA al sector de distribución que comercializa cine europeo, se ha concretado en 2009 en un notable incremento de fondos para la concesión de ayudas económicas a la distribución de películas europeas en España; el importe ha sido de 5.000.000€ frente a la cantidad de 2.500.000€ del año anterior.

Dichas ayudas se conceden para hacer menos costoso el tiraje de copias, subtitulado y publicidad del cine europeo, que sin duda tiene mayores dificultades de comercialización 
frente al cine estadounidense, dando siempre prioridad al Cine Europeo que se distribuya mayoritariamente en versión original. Las ayudas tienen como objetivo prioritario la ampliación del mapa de la distribución mediante la comercialización de las películas en salas a lo largo del territorio.

Las dificultades de las películas que arrancan sin un contrato de distribución llegan cuando ya con la copia estándar en mano no se encuentra distribuidor, algo que suele suceder con óperas primas de realizadores o productores, tenemos el caso reciente de Pa Negre, que tras un paso totalmente desapercibido por las pantallas de cine el azar de los premios de la Academia, la han devuelto a las salas; otras, si su destino no le es adverso, tal vez se hallen un hueco en las semanas flojas del calendario de exhibición, y otras nunca llegarán a estrenarse en un cine comercial.

\section{LA EXHIBICIÓN}

En el año 2010 la tendencia observada respecto a años anteriores es la de una disminución del número de salas activas; el aumento constante del número de salas de exhibición de los años anteriores a 2005 ha empezado a frenarse y su número total comienza a descender; si tuvieron actividad 4080 salas, en 2009 fueron 4.082 y en 2008 fueron 4.140. Se han cerrado salas unas 400 salas desde 2005 pero también ha continuado el proceso de renovación y remodelación.

\section{Salas de exhibición*}

\begin{tabular}{lrrrrrrrrrrr}
\hline & $\mathbf{2 0 0 1}$ & $\mathbf{2 0 0 2}$ & $\mathbf{2 0 0 3}$ & $\mathbf{2 0 0 4}$ & $\mathbf{2 0 0 5}$ & $\mathbf{2 0 0 6}$ & $\mathbf{2 0 0 7}$ & $\mathbf{2 0 0 8}$ & $\mathbf{2 0 0 9}$ & $\mathbf{2 0 1 0}$ & $\mathbf{2 0 1 1}$ \\
\hline $\begin{array}{l}\text { Na de } \\
\text { salas }\end{array}$ & 3.770 & 4.039 & 4.253 & 4.390 & 4.401 & 4.299 & 4.296 & 4.140 & 4.082 & 4.080 & 4.030 \\
$\begin{array}{l}\text { N" de } \\
\text { cines }\end{array}$ & 1.254 & 1.223 & 1.194 & 1.126 & 1.052 & 936 & 907 & 868 & 851 & 860 & 826 \\
\hline
\end{tabular}

Largometrajes estrenados*

\begin{tabular}{lcrrrrrrrrrr}
\hline & $\mathbf{2 0 0 1}$ & $\mathbf{2 0 0 2}$ & $\mathbf{2 0 0 3}$ & $\mathbf{2 0 0 4}$ & $\mathbf{2 0 0 5}$ & $\mathbf{2 0 0 6}$ & $\mathbf{2 0 0 7}$ & $\mathbf{2 0 0 8}$ & $\mathbf{2 0 0 9}$ & $\mathbf{2 0 1 0}$ & $\mathbf{2 0 1 1}$ \\
\hline Españoles & 102 & 122 & 108 & 117 & 128 & 142 & 136 & 139 & 365 & 367 & 351 \\
Extranjer & 1.72 & 1.75 & 1.80 & 1.67 & 1.60 & 1.60 & 1.64 & 1.513 & 1.11 & 1.18 & 1.15 \\
os & 9 & 5 & 8 & 8 & 2 & 6 & 0 & & 6 & 8 & 5 \\
Total & 1.83 & 1.87 & 1.91 & 1.79 & 1.73 & 1.74 & 8 & 6 & 1.48 & 1.55 & 1.50 \\
& 1 & 7 & 6 & 5 & 0 & & 1.77 & 1.652 & 1 & 5 & 6 \\
\hline
\end{tabular}

\begin{tabular}{lcc|c}
\hline \multicolumn{1}{c}{ Recaudación* } & $\mathbf{2 0 0 9}$ & $\mathbf{2 0 1 0}$ & $\mathbf{2 0 1 1}$ \\
\hline $\begin{array}{l}\text { Recaudación de largometrajes } \\
\text { españoles }\end{array}$ & $104.367 .061,15 €$ & $80.277 .621,54 €$ & $99.137 .131,11 €$ \\
$\begin{array}{l}\text { Recaudación de largometrajes } \\
\text { extranjeros }\end{array}$ & $566.676 .723,87 €$ & $582.027 .466,1 €$ & $536.710 .462,62 €$ \\
\hline $\begin{array}{l}\text { Recaudación total } \\
\text { largometrajes }\end{array}$ & $\mathbf{6 7 1 . 0 4 3 . 7 8 5 , 0 2 €}$ & $\mathbf{6 6 2 3 0 5 0 8 7 , 7 €}$ & $\mathbf{6 3 5 . 8 4 7 . 5 9 3 , 7 3 €}$ \\
\hline
\end{tabular}




\begin{tabular}{|c|c|c|c|}
\hline Espectadores* & 2009 & 2010 & 2011 \\
\hline $\begin{array}{l}\text { Espectadores de largometrajes } \\
\text { españoles }\end{array}$ & 17.480 .282 & 12.928 .363 & 15.524 .294 \\
\hline $\begin{array}{l}\text { Espectadores de largometrajes } \\
\text { extranjeros }\end{array}$ & 92.506 .576 & 88.661 .154 & 82.820 .588 \\
\hline $\begin{array}{l}\text { Total espectadores de } \\
\text { largometrajes }\end{array}$ & 109.986 .858 & 101.589.517 & 98.344 .882 \\
\hline
\end{tabular}

\begin{tabular}{|c|c|c|c|c|}
\hline & \multicolumn{4}{|c|}{ Las 25 películas españolas con mayor número de espectadores 2010/11*. } \\
\hline 1 & Torrente 4 & 09/03/2011 & 2.630 .263 & $19.345 .503,32 €$ \\
\hline 2 & Midnight in Paris & $11 / 05 / 2011$ & 1.239 .355 & $7.926 .916,73 €$ \\
\hline 3 & Fuga de cerebros 2 & $02 / 12 / 2011$ & 796.137 & $5.025 .460,16 €$ \\
\hline 4 & Piel que habito, la & 01/09/2011 & 722.960 & $4.585 .877,25 €$ \\
\hline 5 & No habrá paz.... & $16 / 09 / 2011$ & 641.445 & $4.039 .451,98 €$ \\
\hline 6 & También la lluvia & 24/09/2010 & 619.315 & $3.901 .297,52 €$ \\
\hline 7 & Primos & $04 / 02 / 2011$ & 566.410 & $3.545 .363,83 €$ \\
\hline 8 & Mientras duermes & $14 / 10 / 2011$ & 546.085 & $3.517 .590,28 €$ \\
\hline 9 & Águila roja & 20/04/2011 & 502.905 & $3.038 .709,19 €$ \\
\hline 10 & Intruders & 07/10/2011 & 413.970 & $2.652 .127,52 €$ \\
\hline 11 & Un dios salvaje & $18 / 11 / 2011$ & 394.839 & $2.625 .908,13 €$ \\
\hline 12 & Lo contrario al amor & $25 / 08 / 2011$ & 417.384 & $2.562 .519,65 €$ \\
\hline 13 & Cara oculta, la & $16 / 09 / 2011$ & 397.752 & $2.339 .841,08 €$ \\
\hline 14 & Un cuento chino & $17 / 06 / 2011$ & 352.281 & $2.280 .142,13 €$ \\
\hline
\end{tabular}




\begin{tabular}{|c|c|c|c|c|}
\hline 15 & Amigos... & $08 / 07 / 2011$ & 317.470 & $2.006 .250,78 €$ \\
\hline 16 & Voz dormida, la & 23/09/2011 & 313.203 & $1.975 .420,27 €$ \\
\hline 17 & Encontraras dragones & $15 / 03 / 2011$ & 340.760 & $1.974 .945,38 €$ \\
\hline 18 & Pan negro & $15 / 10 / 2010$ & 298.431 & $1.802 .077,55 €$ \\
\hline 19 & $\begin{array}{l}\text { Tres metros sobre el } \\
\text { cielo } 03 / 12 / 2010\end{array}$ & 240.693 & $1.420 .491,82 €$ & \\
\hline 20 & No lo llames amor... & $06 / 05 / 2011$ & 168.883 & $1.038 .972,96 €$ \\
\hline 21 & ¿Para que sirve un oso? & $01 / 04 / 2011$ & 174.474 & $1.038 .823,21 €$ \\
\hline 22 & Kika, supe bruja & $10 / 11 / 2011$ & 158.990 & $965.050,54 €$ \\
\hline 23 & Chico \& Rita & $10 / 12 / 2010$ & 151.012 & $948.538,92 €$ \\
\hline 24 & Eva & $05 / 08 / 2011$ & 131.054 & $850.817,77 €$ \\
\hline 25 & Carne de neón & $25 / 12 / 2010$ & 134.513 & $849.979,79 €$ \\
\hline
\end{tabular}

\section{CUOTA DE MERCADO}

El cine español ha registrado en el año 2011 una cuota de mercado del 15,59\% frente al 12,2\% del año 2010. La cifra más elevada es la que representa el cine estadounidense que ha obtenido un 69,24\%; el cine español ocupa el segundo puesto. La recaudación de cine europeo, excluida España, ha representado un 13,20\% del total, el resto del mercado significó el $1,97 \%$.

\begin{tabular}{|c|c|c|c|c|c|c|}
\hline U.S.A & 578 & 38,37 & 67.903 .059 & 69,04 & $440.277 .037,66$ & 69,24 \\
\hline & & & & & $€$ & \\
\hline U.E.* & 452 & 30,02 & 28.540 .582 & 14,24 & $83.991 .253,09$ & 13,2 \\
\hline Otros & 125 & 8,3 & 1.901.221 & 1,93 & $\begin{array}{r}12.442 .171,05 \\
€\end{array}$ & 1,97 \\
\hline
\end{tabular}

* Excluida España. 
Una nueva situación está observándose en el mercado cinematográfico con la incorporación de la tecnología digital. La digitalización va a cambiar radicalmente el modelo de negocio de la distribución a nivel mundial, modelo que las empresas españolas del sector tendrán que adoptar si quieren mantenerse en el mercado, llegando a los acuerdos precisos con el sector de la exhibición.

Las empresas norteamericanas han invadido el mercado europeo y sus películas, bien promocionadas, son las preferidas del público, por lo general. Constantemente, tanto los distribuidores como exhibidores las contratan y programan, lo que ahoga al resto de las cinematografías. Ante este panorama, conseguir una distribución digna, que haga posible la explotación y amortización del producto, es el mayor reto de las películas realizadas en España. Lo óptimo es conseguir acuerdos de distribución previos al rodaje. Cuando estos acuerdos se producen, la distribuidora se involucra en la producción desde el inicio, adelantando unas cantidades a cuenta de los futuros ingresos de explotación, que ayudan a la financiación del presupuesto total, y se compromete a negociar con el exhibidor la comercialización en unas fechas concretas y razonables.

\section{FINANCIACIÓN}

No todas las películas cuentan con las mismas posibilidades de financiación; las de carácter comercial pueden encontrar fácilmente financiación en las preventas de los derechos de explotación y en préstamos de entidades financieras, amortizables con ayudas públicas sobre la explotación comercial una vez estrenadas. Las películas experimentales o culturales deben apoyarse en las ayudas y subvenciones públicas sobre proyecto.

De conformidad con lo dispuesto en el punto tercero de la Orden CUL/3799/2005, de 29 de noviembre, el importe acumulado por una película de las ayudas previstas en la presente convocatoria no podrá superar el 50 por 100 del coste de la película, ni el 75\% de la inversión del productor en la misma, con el límite máximo en todos los casos de 1.000 .000 de euros.

En la Resolución de 17 de septiembre de 2010, el Instituto de la Cinematografía y de las Artes Audiovisuales, realizó una segunda convocatoria en el año 2010, de ayudas para la amortización de largometrajes.

El acceso a préstamos "blandos" establecidos mediante la línea de financiación creada por convenio entre el ICAA y el ICO, se ha consolidado como sistema fundamental para la producción de largometrajes aunque en 2009 el número de solicitudes ha disminuido considerablemente. Durante el año 2009 el ICAA concedió 54 préstamos por un importe cercano a los 26 millones $€$.

Las productoras españolas siguen un modelo estándar de financiación muy definido:

a. 1/3 en créditos ICO.

b. 1/3 por los derechos de antena de televisión.

c. 1/3 inversión personal o por coproducción, y/o distribución, y/o ventas soporte digital. 
EI ICAA pone a disposición de las productoras varias modalidades de subvención:

- Ayudas a la creación y al desarrollo:

a. Ayudas para el desarrollo de proyectos de películas cinematográficas de largometraje.

b. Ayudas para el desarrollo de guiones para películas de largometraje.

Ayudas a la producción:

a. Ayudas a la producción de largometrajes.

b. Ayudas a la amortización de largometrajes.

- General

- Complementaria

- Ayudas a la producción de cortometrajes: Proyectos de cortometraje. Cortometrajes realizados.

- Ayudas a la producción de series de animación sobre proyecto.

- Ayudas a la producción de películas y documentales para televisión sobre proyecto.

- Ayudas a la minoración de intereses de préstamos bancarios, en sus dos modalidades:

a. Para la exhibición cinematográfica y para la adquisición y mejora de equipamientos de producción cinematográfica.

b. Para la financiación de la producción.

- Ayudas para la realización de obras audiovisuales con empleo de nuevas tecnologías.

- Ayudas a la distribución de películas cinematográficas comunitarias.

- Ayudas a la conservación de negativos y soportes originales.

- Ayudas para la participación y la promoción de películas en festivales internacionales.

En el año 2010 el ICAA dispuso un total de $92.811 .000 €$ de los que concedió en ayudas $81.068 .318,03 €$, o sea el $87,35 \%$ de lo presupuestado. Se han excluido las ayudas para el desarrollo de guiones y la de minoración para la exhibición y equipamientos de producción cinematográfica.

La financiación privada es el recurso inicial, o sea los fondos propios. El coste medio de una película en el año 2010 fue de 2,4 millones de euros; fondos que no tienen por qué ser, solo patrimonio del productor, en ellos entran los préstamos de los bancos $u$ otras entidades de crédito.

Estas empresas exigen dos tipos de garantías:

- Garantía de mercado: Obliga al productor a negociar una venta y explotación con los distribuidores para las distintas formas de explotación comercial (ventanas)

- Garantía de buen fin. Exige al productor que se asegure y llegue a buen fin el proyecto. 
Esto significa que los bancos y entidades de crédito no corren riesgos previsibles. La obtención de dinero con estas empresas ha sido regulada e incentivada con la Ley de exenciones fiscales.

\begin{tabular}{lrr}
\hline \multicolumn{1}{c}{ PRESUPUESTO DE AYUDAS 2010 * } & Sobre el \% \\
\hline Desarrollo de guiones para películas de largometraje & $600.000 €$ & $0,65 \%$ \\
\hline Minoración de intereses. Producción cinematográfica & $2.600 .000 €$ & $2,80 \%$ \\
\hline Producción de largometrajes & $10.000 .000 €$ & $10,77 \%$ \\
\hline Amortización de largometrajes & $56.761 .000 €$ & $61,16 \%$ \\
\hline Conservación de negativos y soportes originales & $850.000 €$ & $0,92 \%$ \\
\hline Distribución de películas comunitarias & $5.000 .000 €$ & $5,39 \%$ \\
\hline Promoción de películas en festivales internacionales & $1.700 .000 €$ & $1,83 \%$ \\
\hline Ayuda sobre proyecto y corto realizado & $1.900 .000 €$ & $2,05 \%$ \\
\hline Proyectos de películas de largometraje & $5.000 .000 €$ & $5,39 \%$ \\
\hline Obras audiovisuales con empleo de nuevas tecnologías & $800.000 €$ & $0,86 \%$ \\
\hline Series de animación sobre proyecto & $2.300 .000 €$ & $2,48 \%$ \\
\hline Producción de películas y documentales para televisión & $5.300 .000 €$ & $5,71 \%$ \\
\hline \multicolumn{1}{c}{ TOTAL } & $\mathbf{9 2 . 8 1 1 . 0 0 0} €$ & $\mathbf{1 0 0 , 0 0 \%}$ \\
\hline \multicolumn{1}{c}{ *Dato REAL } & $\mathbf{8 1 . 0 6 8 . 3 1 8} €$ & $\mathbf{8 7 , 3 5 \%}$ \\
\hline
\end{tabular}

TVE, las televisiones autonómicas, las televisiones privadas y las plataformas digitales colaboraron, con anticipos de derechos de antena, en la financiación de un buen número de proyectos; en muchos casos participaron como coproductoras.

\section{LAS COPRODUCCIONES}

La proporción de participación española en una coproducción, con carácter general puede oscilar entre el 20 y el 80 por ciento del coste de la misma. En coproducciones multipartitas la participación menor no puede ser inferior al $10 \%$ y la mayor no puede exceder del $70 \%$ del coste

Las aportaciones técnicas y artísticas de cada coproductor, así como el rodaje en exteriores o interiores a su cargo, deben ser proporcionales a su participación económica en la película.

Puede haber aportaciones dinerarias superiores a la cuantificación económica de trabajos y servicios realizados por personal técnico y artístico e industrias técnicas de nacionalidad española, pero dicha aportación en dinero del coproductor español no puede ser superior al $50 \%$ de dicha cuantificación. Como excepción pueden admitirse coproducciones financieras sin aportación efectiva de personal y servicios. En este caso la película generará a la productora solamente la ayuda general para la amortización. La aprobación de esta modalidad de coproducciones queda condicionada al balance general existente en relación con los países coproductores. 
En 2010, de las 201 películas producidas 49 se realizaron en coproducción; el hecho de que casi el $24,3 \%$ de ellas sean una coproducción, indica que:

- Que el riesgo que conlleva el hacer cine es asumido por varias empresas.

- Que diversifica su financiación.

- Que existe un interés por realizar películas para conseguir un producto más competitivo.

- Que se garantiza el mercado internacional.

De esta forma no sólo se incrementa la inversión sino que se obtiene garantía de que la película va a cruzar fronteras, pero esta asociación conduce, en ocasiones, a desvirtuar la «identidad» de la película. El día que consigamos que los países de la Unión Europea y los Hispanoamericanos vean nuestro cine de forma regular, existirá una industria cinematográfica española sólida, mientras tanto estaremos hablando de coproducciones puntuales o negocios coyunturales para ir tirando

Está claro que, salvo títulos muy concretos, en España, no se estrena toda nuestra producción cinematográfica, muchas películas se estrenan subrepticiamente o pasan años en espera de ser estrenadas.

\section{LOS DERECHOS DE ANTENA}

El Real Decreto 1652/2004, de 9 de julio, aprueba el Reglamento que regula la inversión obligatoria para la financiación anticipada de largometrajes y cortometrajes cinematográficos y películas para televisión, fue parcialmente modificado por la Ley 96/2007 de 29 de diciembre y

La adquisición por parte de una cadena de televisión de los derechos de antena de una película suele ser una de las condiciones imprescindibles antes de iniciar el rodaje de una película; estos derechos de antena suelen fijarse por 3 años.

La aportación al presupuesto que aportan las televisiones, en mayor o menor porcentaje, dependiendo del gasto total es fundamental en la producción cinematográfica. La existencia de nuevas televisiones privadas y canales digitales ha hecho replantearse, de nuevo, la táctica financiera de los productores.

Los productores reclaman más ayudas para producir películas más competitivas, y las televisiones demandan productos de mayor calidad y comercialidad, pero los primeras no se deciden a invertir sin conocer de antemano como va a rentabilizar su inversión, y las empresas de televisión no compran derechos de emisión si no ven opciones claras de asistencias multitudinarias a las salas, primero, y posteriormente, audiencias millonarias delante del receptor. 


\section{PROGRAMAS EUROPEOS DE FINANCIACIÓN}

El Programa MEDIA se creó en el año 1991, en su última sesión plenaria de enero de 2007 se aprobó el nuevo plan de actuación con una duración estimada de siete años. Su finalidad sigue siendo impulsar el sector audiovisual europeo en todos sus sectores y áreas.

En el área de la producción, el programa MEDIA ha creado un subprograma dedicado a descubrir guiones que atraigan financiación para la realización de obras de ficción. Se trata del programa Script, con sede en Londres. Desde allí se asesora para la realización de guiones, a la vez que se pone en contacto a guionistas y productores, facilitando así una ayuda financiera.

Entre sus objetivos destacan su voluntad de luchar por crear un sector audiovisual fuerte, que refleje y respete la identidad cultural y el patrimonio europeos. También persigue aumentar la circulación de obras audiovisuales europeas dentro y fuera de la Unión Europea, así como fortalecer la competitividad del sector audiovisual europeo, facilitando el acceso a la financiación y la promoción del uso de las tecnologías digitales.

Media Desk España es una de las oficinas de representación del Programa Media de la Comisión Europea, iniciativa de apoyo al sector audiovisual europeo. Desde esta oficina se sirve a los tres sectores básicos de la industria: producción, distribución y exhibición.

Trabaja al servicio de las empresas españolas de los sectores de producción, distribución y exhibición, cinematográfica, audiovisual y de las nuevas tecnologías ofreciendo a dichas empresas un servicio de información, consulta y puesta al día entorno a los ejes prioritarios del Programa MEDIA:

- Producción de películas, obras audiovisuales y multimedia.

- Distribución de películas, obras audiovisuales y multimedia.

- Promoción. Acceso a los mercados europeos audiovisuales.

- Apoyo a Festivales.

- Formación de profesionales.

Apoyo a Proyectos. Para potenciar el patrimonio y los archivos audiovisuales europeos, desarrollar los servicios on-line y mejorar el acceso de los contenidos europeos a los servicios avanzados de difusión digital (cadenas temáticas).

Para el periodo 2007-2013 el Programa MEDIA tiene una dotación de 755 millones $€$. Se han beneficiado de estas ayudas películas españolas como:

- Mar Adentro, de Alejandro Amenábar.

- Los abrazos rotos, de Pedro Almodóvar.

- Balada Triste de Trompeta, de Álex de la Iglesia.

- Buried, de Rodrigo Cortés.

Las siguientes películas españolas han recibido ayuda del Programa MEDIA para ser distribuidas: 
- Los abrazos rotos: en Austria, Bulgaria, Dinamarca, Alemania, Finlandia, Grecia, Noruega, Polonia, Portugal y Suecia.

- La teta asustada: en Alemania y Hungría.

- Las singularidades de una chica rubia (coproducción con Portugal y Francia) en: Austria, Bélgica, Bulgaria, República Checa, Francia, Hungría, Eslovaquia y Reino Unido.

- Triage (coproducción con Irlanda y Francia) en: Bulgaria, República Checa, Dinamarca, Finlandia, Grecia, Noruega, Polonia, Portugal, Rumania, y Suecia.

Otras 6 coproducciones con participación española recibieron ayuda:

- The last flight of Flamingo, de Joao Ribeiro. Coproducción de Portugal, España, Francia, Brasil e Italia.

- Entre Lobos, de Gerardo Olivares. Coproducción de España y Alemania.

- Hexe Lilli - Die Reise nach Mandolan, de Harald Sicheritz. Coproducción de Alemania, Austria y España.

- También la Lluvia, de Iciar Bollain. Coproducción de España y Francia.

- Snowhite, de Pablo Berger. Coproducción de España y Francia.

- Los pasos dobles, de Isaki Lacuesta. Coproducción de España y Suiza.

Además, las siguientes películas españolas fueron distribuidas en diferentes países con la ayuda de EURIMAGES:

- Nomadak TX, documental de Raúl de la Fuente fue distribuido en Bulgaria, Rumania y Hungría.

- 14 kilómetros, de Gerard Olivares, fue distribuido en Turquía.

- Lorenzo Da Ponte, de Carlos Saura, fue distribuida en la anterior República Yugoslava de Macedonia.

\section{PROMOCIÓN}

La promoción es una parte fundamental en la comercialización del producto. La relación con el público no debe incitarse durante los días anteriores al estreno; por el contrario, ha de ser concebida y llevada antes, durante y después del estreno, estrategia en la cual la industria audiovisual, en general, y nuestra cinematografía, en particular, no invierte, aún, cantidades suficientes. Ni en tiempo ni en dinero.

Desde la firma del contrato entre el productor y el director se organizará una campaña de difusión de la película u obra audiovisual. El objetivo es ir creando durante el interés por la historia, y que se convierta en necesidad de ver la película cuando se estrene. Unas veces es el productor quien arranca la promoción y la continúa el distribuidor, otras la inicia el distribuidor; todo depende del contrato de distribución.

Diferentes empresas de promoción y publicidad subrayaban los bajos presupuestos que se manejan en España para la promoción, hay toda una estructura laboral infrautilizada, porque hay buenos cartelistas, buenos fotógrafos de foto-fija, que casi nunca utilizados. Hay que convencer a la Producción de que este trabajo es tan necesario e importante como las otras 
etapas de la producción. En cuanto a las estrategias de promoción, indicar en que no hay fórmulas mágicas, se necesita un equilibrio entre la experiencia y la intuición.

En estos últimos años películas con una producción más grande sí se han desembolsado cifras importantes en este capítulo, por ejemplo, Los otros que invirtió cantidades en su promoción, modificando la costumbre de salir al mercado casi a hurtadillas, como ha sucedido con $\mathrm{Pa}$ negre del 2009 reestrenada por la publicidad adquirida por sus premios GOYA en 2010; las películas españolas que salen al mercado no sobrepasan las 60 ó 70 copias de estreno.

Para realizar una buena campaña de promoción se necesita una agencia profesional, con gran experiencia en el ámbito cinematográfico y que ponga a nuestra disposición:

\section{El jefe de prensa:}

El jefe de prensa se encarga de contactar con los profesionales del periodismo y la comunicación. Los periódicos, las revistas, la radio y los programas de televisión son una publicidad directa que es menester explotar. Su labor cosiste en adelantar datos generales sobre la película para generar noticias sobre ella y concertar la presencia en los rodajes de reporteros, entrevistadores, cámaras y fotógrafos y concertar los llamados «días de prensa».

\section{Gabinete de comunicación:}

El gabinete de comunicación tiene la función consiste en intensificar la expectación del público por ver la película. Crea en el espectador la sensación de estar perdiendo la oportunidad de ver una buena película. Debe tener la necesaria creatividad para suscitar ideas, a partir de la historia narrada, capaces de impresionar al público y atraerlo a las salas.

\section{Consultorías:}

Empresas de estudio de mercado que han desarrollado sofisticados sistemas capaces incluso de predecir el comportamiento de los espectadores meses antes del estreno. Se han creado técnicas con el fin de proporcionar información a los productores y directores para a la toma de decisiones. Cada una de estas técnicas metodológicas evalúa cada una fase del proyecto cinematográfico.

- Test del guión: Permite conocer el interés que suscita; la consistencia del relato y sus momentos más importantes; las posibilidades de los personajes principales. en encuestas individuales proyectivas y reuniones de grupo dirigidos unas 10 personas.

- Test del tráiler: Determina la capacidad persuasiva del mismo, posicionándolo en las preferencias del espectador frente a otros de otras películas mediante encuestas.

- Test de la copia estándar: Estima la respuesta comercial de la película, traza el perfil socio-demográfico, determina los argumentos óptimos de venta, cómo adecuar los soportes promocionales (cartel, eslogan, tráiler) y da pistas sobre las estrategias de marketing y merchandising.

- Test de aceptación: Se realizan una serie de encuestas; encuestas que muestran el grado de popularidad obtenido por la película a pocas fechas después del estreno. 


\section{OTROS SOPORTES PROMOCIONALES}

Además del press-book, los afiches, el cartel y la página web de la película, se realiza el making off, en español "cómo se hizo". Es una filmación que nos muestra el proceso interno de realización de una película. Un documental de unos 20 minutos que cuenta la idea básica de la película y particularidades y/o anécdotas del rodaje; con entrevistas al director y a los protagonistas y una incursión a las técnicas utilizadas al rodar las distintas secuencias. Se asiste al rodaje, a la creación y filmación de los efectos especiales (si los hubiere), al montaje y postproducción de la película. Se complementa con comentarios del director, de los protagonistas, de responsables técnicos o promotores de la película. Su fin es principalmente promocional o como complemento de las copias en formato DVD. El equipo suele estar formado por un reducido grupo de técnicos: guionista/realizador y su ayudante y un operador de cámara y su ayudante.

Otra de las prácticas habituales en las fechas próximas al estreno es la aparición del director y los intérpretes en los diversos medios de comunicación. Sobre todo en las distintas cadenas de televisión; es un arma esencial para crear corrientes favorables de opinión.

Casos de promoción impecable, que se tradujeron en éxito de taquilla, son las promociones que suelen realizar Pedro Almodóvar, Alejandro Amenábar o Santiago Segura.

\section{AYUDAS INTERNACIONALES}

El programa Media de la Unión Europea puso en marcha en 1997 un plan de ayudas con la introducción del sistema de "apoyo automático» que se sumaba al ya existente "sistema selectivo». El nuevo sistema ha permitido que una veintena de distribuidores españoles reciban una ayuda directa para la distribución de películas europeas, calculada sobre la base de entradas vendidas.

\section{Mercados de distribución:}

Una buena parte del porcentaje de compras se realiza en los mercados y festivales que cada año se celebran en distintos países del mundo, sobre todo en Europa y Norteamérica. Le MIF, Marche Internacional du Film, mercado asociado al Festival Internacional de Cannes; el mercado audiovisual iberoamericano, MIDIA, el American Film Marquet y el MIFED de Milán son las cuatro citas de más interés. Para los distribuidores españoles y europeos el principal es el MIF.

\section{Exhibición:}

Un mercado dominado por la omnipresencia de las producciones norteamericanas es realmente excepcional que un exhibidor acepte la proyección en una sala o en una de sus cadenas las producciones españolas o comunitarias que no vengan avaladas por el nombre de un director consagrado o una fortísima campaña de promoción inspirada por la distribución de una multinacional. Sobre todo teniendo en cuenta que la figura del exhibidor como empresario individual prácticamente ha desaparecido, y las salas de proyección se agrupan en cadenas, al mando de una empresa de gestión, muchas veces otra multinacional norteamericana. 
No obstante, desde el comienzo de los años 2000, la confianza de los exhibidores hacia las películas españolas ha aumentado, pero de manera no muy significativa; ello ha contribuido a mejorar la situación de la industria.

\section{Festivales y prestrenos}

Los primeros pases públicos de una película se suelen dar en los festivales de cine a los que la productora decide enviar una copia del film. Es la toma de contacto del producto con la crítica y el público, un escaparate que a veces recompensa con premios en metálico y, según la importancia del certamen, sirve para prestigiar a sus creadores, incrementar la taquilla o conseguir contratos de distribución.

El preestreno es un elemento promocional más, una cita a la que acuden los medios de comunicación y que luego otorgarán un espacio para la película en sus ámbitos radiofónicos, televisivos o impresos. En definitiva, es la presentación en sociedad de la obra.

\section{Premios nacionales e internacionalles}

Los premios suelen ser el reconocimiento a una labor profesional. En España se celebran en torno a $\mathbf{3 0 0}$ festivales de cine, desde categoría internacional a premios locales o de barrio, y cada uno con su Primer Premio. Solo reseñaré alguno de los premios más conocidos, sin menos cabo de los no mencionados, vaya desde aquí mi total reconocimiento.

\section{- Premio Nacional de Cinematografía:}

Este premio está destinado a recompensar la aportación más sobresaliente en el ámbito cinematográfico español durante el año anterior a su concesión, o labor profesional desarrollada durante ese mismo año. En casos excepcionales, también se otorga como reconocimiento a la trayectoria profesional.

Premiados en el período 2001-2012:

2012. Dạ. Ivonne Blake - Vestuario.

2011. D. Agustí Villaronga - Director y Guionista.

2010. D. Álex de la Iglesia - Director.

2009. Dạ Ma Isabel Verdú Rollán (Maribel Verdú) - Actriz.

2008. D. Javier Encinas Bardem (Javier Bardem) - Actor.

2007. D. Alberto Iglesias - Compositor de Música para Cine.

2006. D. Joaquín Jorda - Director y Guionista.

2005. D. Manuel Gutiérrez Aragón - Director.

2004. D. Javier Aguirresarobe Zubía - Director de Fotografía.

2003. Da Mercedes Sampietro Marro - Actriz.

2002. D. José Luis Borau Moradell - Director.

2001. D. José Luis Guerín - Director.

- Premios "GOYA":

La Academia de las Artes y Ciencias Cinematográficas de España instituyó los Premios Goya hace 25 años; con ellos se premia cada año, por votación de sus Académicos, a la mejor película y a los mejores profesionales del elenco artístico y 
técnico del año anterior respecto al del que se entrega. La condición sine quanum que han de tener las películas es que han de haber sido estrenadas.

La Academia de las Artes y Ciencias Cinematográficas de España también tiene instituidos otros galardones y premios:

- Medalla de Oro

Es otorgada, en reconocimiento a quienes han contribuido con su trayectoria profesional a mejorar el cine español en el aspecto industrial o artístico. Se concede desde 1991.

- Premio González Sinde

Se otorga a instituciones o personas que emplean el medio cinematográfico para la consecución de fines sociales. Se concede desde 1998.

\section{- Premio Muñoz Suay}

Se concede al mejor o los mejores trabajos de investigación histórica sobre cine español. Se concede desde 1991; fue interrumpida su concesión entre el año 2003 y 2007.

\section{- Premio Segundo de Chomón}

Establecido para reconocer el mérito de las aportaciones técnicas que han redundado en beneficio de la industria cinematográfica. Se concede desde el año 2000.

\section{- Premios Oscar:}

Españoles premiados en el período 2001-2010:

2008:

Penélope Cruz: Oscar a la mejor actriz de reparto por "Vicky Cristina Barcelona".

Dirección: Woody Allen.

Países: España / EE.UU.

2007:

Javier Bardem: Oscar al mejor Actor de Reparto por "No es país para viejos".

Dirección: Ethan Coen, Joel Coen.

País: EE.UU.

2004:

Mar adentro: Oscar a la mejor película de habla no inglesa

Dirección: Alejandro Amenábar.

Países: España / Francia / Italia.

2002:

Hable con ella: Oscar al mejor guión original. Pedro Almodóvar.

País: España. 


\section{- Premio Cinematográfico José María Forqué:}

Concedidos por EGEDA (Entidad de Gestión de Derechos Audiovisuales), a la mejor producción española estrenada el año anterior. Desde 2003 se incorporan la Medalla de Oro de EGEDA a la trayectoria de un productor en el cine español y el Premio Especial EGEDA al mejor largometraje documental y/o de animación. A partir del año 2010 se entregan los premios a la mejor interpretación masculina y femenina.

\section{- Medallas CEC (Premio Círculo de Escritores Cinematográficos):}

Entregadas por el Círculo de Escritores Cinematográficos a las mejores producciones cinematográficas del año. La ceremonia de entrega se celebra a mediados del mes de enero desde el año 1945 . Este premio estuvo suspendido entre 1985 y 1989.

\section{- Premis Gaudí:}

Otorgados por la Academia del Cine Catalán, a las mejores producciones cinematográficas catalanas del año. Ceremonia: principios de febrero. En 2009 sustituyeron al Premio Barcelona de Cine, creado en 2002.

\section{- Premis Túria:}

Establecidos por la Comunidad Valenciana y el semanario valenciano 'Cartelera Turia', en reconocimiento a los méritos cinematográficos, televisivos y otros varios. Ceremonia: mediados, finales de noviembre. Se conceden desde el año1996.

\section{- Premios Mestre Mateo:}

Otorgados por la Academia Galega do Audiovisual, a las mejores producciones audiovisuales gallegas del año. En el año 2002 sustituyeron a los Premios Agapi, que se concedieron entre 1996 y 2001.

\section{- Premios Berlanga (Premios Valencianos de Cine):}

Establecidos por el EAVF Empresas Audiovisuales Valencianas Federadas, a los mejores audiovisuales valencianos. Creados en 2008.

\section{- Premios Fotogramas de Plata}

Entregados por la Revista Fotogramas. Los premios a las películas nacionales y extranjeras los conceden la crítica especializada y los concedidos a los intérpretes son elegidos por el público. Se conceden desde el año 1950. Son los más antiguos y gozan de un gran reputación.

\section{- Premios Unión de Actores:}

Acordados por la asociación profesional Unión de Actores, son concedidos a las mejores actuaciones en Teatro, Cine y Televisión. Se conceden desde 1991 y empiezan a tener gran celebridad entre los actores y el público. 


\section{- Premios ACE}

Otorgados por la Agencia del Cortometraje Español. Creados para reconocer la labor de apoyo y promoción del cortometraje a los medios de Prensa, Radio, TV, Internet, de entidades o empresas públicas o privadas, así como a personas que destaquen por su trabajo en el cortometraje. Se otorgan desde el año 2007.

- Premio Zinemira (Zinemira - Gala de Cine Vasco)

Nuevo premio en el marco del Festival Internacional de Cine de San Sebastián; lo concede la Consejería de Cultura del Gobierno Vasco, a una personalidad destacada del cine vasco, desde el año pasado.

\section{Referencias bibliográficas}

Revista digital: Cuadernos de Documentación Multimedia no 19 de marzo de 2008. http://multidoc.ucm.es/cdm/

\section{ICAA: http://www.mcu.es/cine:}

- Información general. Cine y Audiovisuales.

- Datos de películas calificadas 2001-2011.

- Evolución cinematográfica 2001-2011.

- Boletines informativos 2001-2011.

- El cine y el vídeo en datos y cifras 2001-2011.

- Memorias de ayuda a la cinematografía.

- Premios a la cinematografía.

Libros del Cine Español: 2000-2008 y pen drive's 2009-2010 del ICAA.

Revista ACADEMIA, Academia de las Artes y de las Ciencias Cinematográficas de España. Los 12 números de información anual del mercado cinematográfico español, desde 2001 a 2012. 